\title{
University STEM students' perceptions of creativity in non-routine problem-solving
}

\author{
$\begin{array}{lll}\text { P. E. L. Murphy } & & \text { T. } \text { Evans }^{2} \quad \text { S. Klymchuk } \\ & \end{array}$ \\ J. Novak $\quad$ J. M. Stephens ${ }^{5} \quad$ M. O. J. Thomas ${ }^{6}$
}

(Received 27 January 2020; revised 16 May 2020)

\begin{abstract}
The primary purpose of this study is to investigate students' perceptions about the characteristics of creativity and engagement in solving non-routine problems. It involved 64 science, technology, engineering, and mathematics (STEM) university students, who participated in a two-year research project in New Zealand during which participants were given opportunities to utilise puzzle-based learning in their courses. Comparing open-ended responses of two surveys, this article focuses on student perceptions about attributes of creativity in nonroutine problem-solving. These results have pedagogical implications for tertiary STEM education.
\end{abstract}

DOr:10.21914/anziamj.v61i0.15052, C) Austral. Mathematical Soc. 2020. Published 2020-07-27, as part of the Proceedings of the 14th Biennial Engineering Mathematics and Applications Conference. ISSN 1445-8810. (Print two pages per sheet of paper.) Copies of this article must not be made otherwise available on the internet; instead link directly to the DOI for this article. 


\section{Contents}

1 Introduction, theory and literature

C153

2 Method of study

C156

3 Results

C156

4 Discussion

C160

5 Conclusion

C161

\section{Introduction, theory and literature}

Non-routine problem-solving is emerging as the pinnacle of creativity in universities. The model of teaching, which is known as puzzle-based learning (PzBL), has been evolving in many schools and universities. Today, characteristics of PzBL often include that it is driven by challenging, non-routine problems, that learners work in small groups, and lecturers play the role of facilitators [12]. By definition, a non-routine problem is one for which students do not have a ready-made method of solution that they can apply to solve it, but which is within the scope of their knowledge base. An example of a non-routine problem or a puzzle from a related study [10] is: Fifty-five players start a tennis tournament. How many matches will be played if a player who loses a match leaves the tournament? An appropriate approach to solving this puzzle is the 'start at the end' strategy - think about the number of winners at the end, 54 players are eliminated so the correct answer is 54 matches. It was argued that, while the procedural method was normally used to solve routine problems [6], puzzles were not solved by rote but reinforced thinking skills [17].

A number of intellectual qualities that might contribute to creative thinking have been considered. One source of creative thinking is 'divergent- 
production' (DP) abilities. Four components are considered as important DP abilities: fluency, flexibility, originality, and elaboration. Another source of creative thinking is 'transformation' abilities, which pertain to one's ability to connect old and new knowledge and hence create new ideas. One crucial characteristic of this ability is a readiness to be flexible, where flexibility leads to reorganization and reinterpretations [8].

An advantage of studying creative abilities is that it can shed light on other mental functions [8]. For example, in the field of mathematics, some researchers have found that flexible thinking may promote mathematical creativity. Aspects of flexibility, or versatililty, that have been proposed include adaptive expertise and versatile thinking [18]. Adaptive expertise refers to the flexible and creative application of meaningfully learned mathematical procedures [1]. Students who have developed this tend to go beyond routine competencies and are more flexible, innovative, and creative, and are able to understand why procedures work, to modify procedures, and to invent new ones [9]. In contrast, students displaying versatile thinking are able to: translate within and between representations; interact conceptually with representations; switch between perceptions of a mathematical entity as a process or an object; and exploit the power of visual schemas by linking them to relevant analytical ones [18].

Creativity is a process that is often required in the solving of problems. Some constituent parts of this creative process include originality or divergent thinking (an ability to use a new technique to solve a problem), flexibility (an ability to think beyond the obvious, turning ideas and materials to new, different and unusual approaches to solve a problem), fluency (an ability to identify ideas and possible solutions to a problem), and elaboration (an ability to explain coherently the details of certain mathematical procedures or solutions) [7]. One study showed that Grade 10 mathematics students were "moderately creative", demonstrating fluency, flexibility and originality, but those students who were considered most fluent and most flexible were able to provide step-by-step procedures and detailed solutions to get the correct answers [5]. 
Research on problem-solving contributes to an understanding of creativity in education, particularly with regard to non-routine problems. Some problems may be amenable to Pólya's [14] four-step approach to solving problems. In this approach, students can: 1) understand the tasks before they 2) plan and 3) implement their strategies, and finally 4) check and interpret their solutions. This model of problem-solving aligns with a framework of mathematical problem-solving that includes knowledge, heuristics, beliefs and meta-cognitive skills [16]. However, in order to solve non-routine problems, Wallas [20] suggested that creative thinking is required and involves 1) preparation (identify the problem, information gathering), 2) incubation (unconscious processing of information, cognitive processing), 3) illumination (insight, a 'sudden' discovery of a solution, 'a-ha' experience, a schema is completed), and 4) verification (test and evaluate new ideas). Students may go through each stage of creative thinking in a recursive manner [15], since the most appropriate solutions will require insightful thinking and verification. Thus more time will be spent on revisiting every stage. In this way, students could recursively employ Wallas' four-stage creative thinking, without necessarily adhering to Pólya's four-step problem-solving approach per se.

While fostering creativity is by no means the only solution to future-proofing undergraduates, incorporating the creativity required in PzBL in universities could have a positive impact on student learning and the development of professional skills. Some ways in which this could be done include having practitioners model creative behaviours [15], or design a creativity-driven engineering curriculum [2, 11, 19]. Some PzBL researchers have reported positive benefits for their students: the development of generic thinking of engineering mathematics students [10] and improved problem-solving abilities of computer science students [3] as well as engineering mathematics students [17]. In engineering faculties, researchers argue that puzzles could be recast in an engineering context and that solving puzzles allows them to model good problem-solving behaviour through the use of diagrams [17]. In addition, some researchers argue how PzBL could enhance students' professional engineering skills since the engineering problems aligned well with problem-solving skills 
acquired through PzBL [13]. These skills could also improve a wide range of employability skills [4], because many high-tech companies now require problem-solving and creative thinking skills from their job candidates and look for these skills in their job interviews.

\section{Method of study}

As part of a larger New Zealand research project, this study examined students' views of problem-solving and creativity by utilising online questionnaires before and after teaching interventions. In 2018, over 680 STEM participants from four New Zealand tertiary institutions, Auckland University of Technology, University of Auckland, Manukau Institute of Technology, and Whitireia Polytechnic took part in PzBL during lectures. The participants $(\mathrm{N}=64$, $9 \%$ response rate) completed both questionnaires. The sample consisted of 36 males, 27 females, and 1 gender diverse; 58 participants were younger than 25 years old and the remaining six participants were over 25 years old. Their 12 -week courses included astronomy, computing, engineering and mathematics and, with the full collaboration of the lecturers, the PzBL teaching model was implemented in each course. While the major course components (tutorials, assignments, tests and examinations) were not altered, the lecturers facilitated PzBL by regularly allowing three to five minutes during each lecture for one to three puzzles to be presented and solved. During this time the students worked in a small group or individually to solve the puzzles and, in addition, the lecturers gave regular feedback and modelled problem-solving activity.

\section{Results}

In order to investigate students' views of problem-solving and creativity, the questionnaire data were analysed using mixed methods. The researchers extracted students' comments (as shown in this section within the parentheses) and compiled descriptive statistics such as percentages of 'Yes' and 'No'. In this section, the percentages indicate 'Yes' responses of participants with 
justifications. In the following we report on the questions and the answers.

Question 1: Do you think solving puzzles can enhance your problem-solving skills? Yes/No because

A majority of the participants $(\mathrm{N}=64)$ in the pre-survey $(92 \%)$ and the post-survey $(92 \%)$ agreed that solving puzzles could enhance their problem-solving skills. Since the puzzles were generic but challenging, the participants did not require specific mathematical knowledge but relied on their thinking skills ("I am literally solving problems when solving the puzzle and it trains the thinking process in an entertaining way."). In this way, they could recognise that the puzzles were enabling them to think differently ("It brings about a new way of thinking, this new way of thinking develops a new understanding of any situation and often helps prove there is normally an easy way to do things."). They also used their logical thinking coupled with novel strategies to solve puzzles ("We establish systematic ways to solve puzzles or issues and apply those strategies."). Furthermore, critical thinking helped them to consider these different approaches to solving puzzles ("Think critically and in a different perspective."). The idea of the need to have, and develop, flexible thinking and a growth mindset was also described ("By practicing a wide variety of puzzles can help create a flexible way of thinking. It's developing a mindset that allows flexibility in thinking. Solving puzzles helps problem solving skills because of it flexes the mind.").

The responses also focused on approaches to solving the problems (19\% pre-survey, $13 \%$ post-survey). The puzzles encouraged students to be flexible and employ a variety of approaches, including a systematic method ("Yes, as it will help me think of ways and different approaches."). By using flexibility leading to appropriate approaches, students could often find the correct solutions ("The most obvious answer was usually incorrect, forcing us to find other ways of getting correct solutions."). Another feature associated with finding solutions is an ability to learn 
from failure ("It is problem-solving, the ability to pivot strategies upon failure is also another method of solving problems by deduction."). Since the puzzles were usually very challenging and difficult to solve, they required creative cognitive abilities along with commitment to successfully find the correct solutions ("Solving puzzles forces you to think critically and creatively about the components of a puzzle, and these skills can be drawn on when solving difficult problems which may seem unsolvable."). Few participants (26\% pre-survey, 20\% post-survey) stated how constant practice enhanced their problem-solving abilities and self-confidence in problem-solving ("Puzzles are problems, practice makes you better the more you practice solving problems the better you become at it."; "It increases your level of confidence and knowledge of when you're utilizing your problem-solving skills.").

Some participants (17\% pre-survey, 11\% post-survey) indicated how PzBL could sharpen their abilities to apply their mathematical knowledge and solve real-world problems. They felt that problem-solving abilities helped them to analyse problems carefully and would assist them to make informed decisions about solving real-life problems when they start work ("The way the mind has been trained from solving puzzles can be implemented into real world problems, helping problem-solving skills."; "You can see how math translate [sic] the real world around us.").

Question 2: Do you think solving puzzles can enhance your creativity? Yes/ No because

The responses to this second question showed that $86 \%$ (pre-survey) and $84 \%$ (post-survey) of participants agreed that solving puzzles could enhance their creativity. A common survey response to both Questions 1 and 2 defined creativity in terms of the need to 'think outside the box': 12 times (pre-survey), and 15 times (post-survey). About half the participants (47\% pre-survey, $57 \%$ post-survey) thought they were less likely to focus on finding a single heuristic approach to get the correct 
answer ("It forces you to look outside the obvious first glance answer and think about other possibilities outside of the obvious.").

Other responses to this question (42\% pre-survey, $45 \%$ post-survey) focused on notions of thinking differently. They stated that instead of applying a formula, they needed to access their prior knowledge and employ creative thinking in the problem-solving ("It teaches us to rely on our knowledge but not necessarily follow the formula of what we've been taught, but instead a good balance of prior knowledge and thinking 'outside of the box'."). They agreed there was a need to think beyond commonly accepted ideas ("It helps you see that there are a lot of different ways to doing the same task or one standard way of doing a range of things.") and to interpret the questions in different ways ("It requires us to look at the question in different perspective [sic] and visualise the situation in our head.").

Question 3: Do you think solving puzzles can benefit you in the future? Yes/No because

In responding to this third question, the vast majority of participants (94\% pre-survey, 92\% post-survey) agreed that solving puzzles could benefit them in the future. Some participants (32\% pre-survey, $28 \%$ postsurvey) specified particular ways they perceived puzzles would be beneficial in their future career and career opportunities, such as in data science and astronomy ("I hope to pursue a career in data science and science technologies."; "Absolutely, I am aiming to work as an Astronomer - possibly in the field of astrophysics, and math/physics are concerned with a multitude of real-world puzzles."). They also believed that employers expected their employees to utilise problem-solving skills with clients and that they would test these skills in job interviews ("I think employers look for people with good problem-solving skills."; "Employers look for people who have problem solving skills. You are tested on this in interviews.").

In terms of personal growth and development, many participants 
(47\% pre-survey, $59 \%$ post-survey) commented that they enjoyed solving puzzles and felt a sense of achievement and thought it developed their creativity, as well as problem-solving skills ("I really enjoy them and get joy from them and a feeling of satisfaction and self-worth and pride when completing them."; "It gives me feeling of achievement."; "It enhances creative and problem-solving skills."), Some (21\% pre-survey, $11 \%$ postsurvey) stated that puzzles could enhance their problem-solving skills in their daily lives, at work ("It builds skills that are useful in the workplace/everyday life), and when solving real world problems ("You will learn problem solving skills that you can apply in the real world."; "The world is evolving and there will be many puzzles to solve in this life, both as a society as a whole and personally."). Moreover, they expected their problem-solving skills to help with solving complex life problems ("Faced non-traditional problems in the real world.").

\section{Discussion}

This study examined students' perspectives on non-routine problem-solving. Their comments focused mainly on thinking skills that drives non-routine problem-solving, which was reinforced by a similar study [10]. The results suggest that problem-solving is a process of creative thinking following Wallas' four-stage creative thinking [20], involving: understand the problems (preparation) and apply heuristic strategies and practise non-routine problems (incubation). Students' comments about constant practice and learning from failure revealed 'a-ha' moments in solving puzzles (illumination). The chance to verify their solutions was made possible through group discussions and lecturers' feedback (verification). Along with the cognitive development, the data also implied meta-cognitive abilities in problem-solving [16]. The study showed that the participants believed that PzBL enhanced their creative problem-solving skills as well as self-confidence in problem-solving.

Most of the participants described the characteristics of creativity in solving puzzles. This study indicated that the participants perceived creativity as a 
process of showing 'transformation' abilities and DP abilities through their readiness to be flexible and original in solving puzzles $[8,7]$. The participants displayed flexibility in solving the puzzles and demonstrated this by being willing to change their perspectives and employ different heuristic approaches to get the correct answers. They also showed divergent thinking as they worked out different ways of solving the puzzles. Consistent with other studies [1, 9], this study has indicated the potential of PzBL to enhance student flexibility and divergent thinking, which, in turn, leads to improved creativity.

The participants were willing to engage in PzBL because they perceived the practical and personal benefits of problem-solving. The practical benefits included improved performance at job interviews and better professional skills. Their perceived personal benefits pertained to problem-solving skills, thinking skills, enjoyment, and personal satisfaction. Interestingly, the participants tended to place more emphasis on the personal benefits than the practical benefits of PzBL. As first-year students, some of them might not have had sufficient work experiences and lack appreciation of the complex world of professional work and its nuances. Hence, they may not yet be fully able to realise the likely impact of problem-solving on their future professions. Consistent with past studies [13, 4], this research suggests that while some participants recognised PzBL to be an integral part of the course, they tended to adopt a utilitarian view of education, which was driven by their career aspirations.

\section{Conclusion}

Incorporating PzBL in STEM courses not only impacts the development of students' thinking skills but also reinforces positive attitudes. This study revealed that students perceived problem-solving in terms of divergent thinking, flexibility and originality, which enhanced their creativity. Furthermore, their perceived benefits of PzBL underpinned their positive attitude towards learning. Therefore, teaching non-routine problems in STEM courses has the 
potential to change the paradigms of learning - from systematic problemsolving to creative problem-solving; from the acquisition of information to the development of creativity. Future STEM education research would serve to validate the potential positive impact of PzBL.

Acknowledgements This study forms part of a collaborative research project (Investigating the impact of non-routine problem-solving on creativity, engagement and intuition of STEM tertiary students) funded by a grant from the Teaching and Learning Research Initiative Scheme in New Zealand.

\section{References}

[1] A. J. Baroody and A. Dowker. The development of arithmetic concepts and skills: Constructive adaptive expertise. Routledge, 2013. URL: https://www .routledge.com/The-Development-of-ArithmeticConcepts-and-Skills-Constructive-Adaptive/BaroodyDowker/p/book/9780805831566 (cit. on pp. C154, C161).

[2] S. A. Costa. "Puzzle-based learning: An approach to creativity, design thinking and problem solving. Implications for engineering education". In: Proceedings of the Canadian Engineering Education Association (CEEA) (2017). DOI: 10.24908/pceea.v0i0.7365 (cit. on p. C155).

[3] N. Falkner, R. Sooriamurthi, and Z. Michalewicz. "Teaching puzzle-based learning: Development of transferable skills". In: Teach. Math. Comput. Sci. 10.2 (2012), pp. 245-268. DOI: 10.5485/TMCS. 2012.0304 (cit. on p. C155).

[4] A. Fisher. Critical thinking: An introduction. Cambridge University Press, 2011. URL: https://www. cambridge.org/us/education/ subject/humanities/critical-thinking/critical-thinking2nd-edition/critical-thinking-introduction-2nd-editionpaperback?isbn=9781107401983 (cit. on pp. C156, C161). 
[5] E. C. Fortes and R. R. Andrade. "Mathematical creativity in solving non-routine problems". In: The Normal Lights 13.1 (2019). URL: http://po.pnuresearchportal.org/ejournal/index.php/ normallights/article/view/1237 (cit. on p. C154).

[6] P. Gnädig, G. Honyek, and K. F. Riley. 200 puzzling physics problems: With hints and solutions. Cambridge University Press, 2001. URL: https:

//www . cambridge.org/us/academic/subjects/physics/generaland-classical-physics/200-puzzling-physics-problems-hintsand-solutions? format=AR\&isbn=9780521774802 (cit. on p. C153).

[7] J. P. Guilford. Characteristics of Creativity. Illinois State Office of the Superintendent of Public Instruction, Springfield. Gifted Children Section, 1973. URL: https://eric.ed.gov/?id=ED080171 (cit. on pp. C154, C161).

[8] J. P. Guilford. "Creativity: Yesterday, today and tomorrow". In: J. Creative Behav. 1.1 (1967), pp. 3-14. DOI: 10.1002/j.2162-6057.1967.tb00002.x (cit. on pp. C154, C161).

[9] G. Hatano and Y. Oura. "Commentary: Reconceptualizing school learning using insight from expertise research". In: Ed. Res. 32.8 (2003), pp. 26-29. DOI: 10.3102/0013189X032008026 (cit. on pp. C154, C161).

[10] S. Klymchuk. "Puzzle-based learning in engineering mathematics: Students' attitudes". In: Int. J.Math. Ed. Sci. Tech. 48.7 (2017), pp. 1106-1119. DOI: 10.1080/0020739X.2017.1327088 (cit. on pp. C153, C155, C160).

[11] B. Martz, J. Hughes, and F. Braun. "Developing a creativity and problem solving course in support of the information systems Curriculum." In: J. Learn. High. Ed. 12.1 (2016), pp. 27-36. URL: https://files.eric.ed.gov/fulltext/EJ1139749.pdf (cit. on p. C155). 
[12] Z. Michalewicz, N. Falkner, and R. Sooriamurthi. Puzzle-based learning: An introduction to critical thinking and problem solving. Hybrid Publishers, 2011 (cit. on p. C153).

[13] B. Parhami. "A puzzle-based seminar for computer engineering freshmen". In: Comp. Sci. Ed. 18.4 (2008), pp. 261-277. DOI: 10.1080/08993400802594089. (Cit. on pp. C156, C161).

[14] G. Pólya. How to solve it: A new aspect of mathematical method. Princeton University Press, 2004. URL: https:

//press.princeton. edu/books/paperback/9780691164076/howto-solve-it (cit. on p. C155).

[15] M. A. Runco. Creativity: Theories and themes: Research, development, and practice. Elsevier, 2014. URL:

https://www.elsevier.com/books/creativity/runco/978-0-12410512-6 (cit. on p. C155).

[16] A. H. Schoenfeld. Mathematical problem solving. Elsevier, 2014. URL: https://www.elsevier.com/books/mathematical-problemsolving/schoenfeld/978-0-12-628870-4 (cit. on pp. C155, C160).

[17] C. Thomas, M. Badger, E. Ventura-Medina, and C. Sangwin. "Puzzle-based learning of mathematics in engineering". In: Eng. Ed. 8.1 (2013), pp. 122-134. DOI: 10.11120/ened.2013.00005 (cit. on pp. C153, C155).

[18] M. O. J. Thomas. "Developing versatility in mathematical thinking". In: Med. J. Res. Math. Ed. 7.2 (2008), pp. 67-87 (cit. on p. C154).

[19] A. Valentine, I. Belski, and M. Hamilton. "Developing creativity and problem-solving skills of engineering students: A comparison of web and pen-and-paper-based approaches". In: Eur. J. Eng. Ed. 42.6 (2017), pp. 1309-1329. DOI: 10.1080/03043797.2017.1291584 (cit. on p. C155).

[20] G. Wallas. The art of thought. Solis Press, 1926 (cit. on pp. C155, C160). 


\section{Author addresses}

1. P. E. L. Murphy, Mathematical Sciences, Auckland University of Technology, , Auckland, New ZEALAnd mailto:priscilla.murphy@aut.ac.nz orcid:https://orcid.org/0000-0003-2904-7358

2. T. Evans, Department of Mathematics, University of Auckland, Auckland, NEW ZEALAND

3. S. Klymchuk, Mathematical Sciences, Auckland University of Technology, , Auckland, New ZeALAnd

4. J. Novak, Department of Mathematics, University of Auckland, Auckland, New ZEALAND

5. J. M. Stephens, Department of Mathematics, University of Auckland, Auckland, New ZeALAND

6. M. O. J. Thomas, Department of Mathematics, University of Auckland, Auckland, New ZEALAND 